\title{
Fabrico Industrial do Carbonato de Sódio no Século XIX: Exemplos Precoces de Química Verde e Ecologia Industrial
}

\author{
Adélio A. S. C. Machado *
}

$U_{m}$

ma análise dos dois processos industriais que foram sucessivamente inventados nos séculos XVIII e XIX para o fabrico do carbonato de sódio (Processos Leblanc e Solvay) mostra que os problemas resultantes da polvição pelos resíduos do primeiro foram um dos factores que pressionaram o desenvolvimento do segundo - o que constitui um exemplo precoce de substituição de processos polventes hoje recomendada pela Química Verde. No entanto, a substituição foi lenta, tendo o Processo Leblanc resistido à competição durante algumas décadas devido, em parte, ao desenvolvimento de um sistema eco-industrial que realizava o aproveitamento dos seus resíduos polventes - o que mostra que a então nascente Indústria Química proporcionou logo um exemplo temporão de Ecologia Industrial, hoje preconizada pela Engenharia Química Verde. O Processo Leblanc foi também suportado por factores de natureza não tecnológica, o que evidencia o papel importante que os factores sócio-económicos podem assumir na resistência à substituição de processos.

Num artigo anterior [1], discutiu-se a biografia de Alfred Nobel como um praticante precursor da Química Verde $(\mathrm{QV})$ - mostrou-se que ele tinha adoptado precocemente posturas que se integram perfeitamente nas preconizadas agora pelos Doze Princípios da QV [2,3]. No presente artigo, apresenta-se outro exemplo temporão de QV: revê-se a história da produção industrial do carbonato de sódio ("soda") com o objectivo de mostrar que a mudança, ocorrida predominantemente ainda no século XIX, do Processo Leblanc, um processo muito poluente de síntese do composto, para o Processo Solvay, mais inócuo para o ambiente, constituiu um primeiro exemplo da substituição de uma síntese tradicional por uma síntese verde (na nomenclatura actual) - revelando que, afinal, certas atitudes hoje consideradas inovatórias no âmbito da nova abordagem da química que é a QV começaram a manifestar-se na Indústria Química logo aquando da sua formatação inicial, mais de um século antes da emergência da QV.

Além do objectivo anterior, este artigo tem um segundo objectivo: analisar as razões porque os dois processos

\footnotetext{
* Departamento de Química da Faculdade de Ciências da Universidade do Porto, R. Campo Alegre, 687 4169-007 Porto

amachado@fc.up.pp
}

coexistiram durante dezenas de anos, isto é, porque a substituição do Processo Leblanc pelo Processo Solvay foi lenta - o primeiro resistiu ao desmantelamento, apesar do segundo ser tecnologicamente superior [4,5]. A discussão mostra que isso se deveu, em parte, à utilização do Processo Leblanc como o cerne de um sistema de Ecologia Industrial [6-8] - o que constitui um exemplo de emergência temporã desta, que formalmente só surgiu nos finais do século XX. O problema da substituição de produtos e processos tem presentemente grande actualidade no âmbito da $\mathrm{QV}$, já que esta prescreve, como objectivo global decorrente dos Doze Princípios, a substituição dos perigosos por alternativas benignas - por exemplo, a substituição vai ser pressionada no futuro próximo pelo REACH [9]. No entanto, há barreiras de índole não tecnológica a vencer na realização da substituição, que também são exemplificadas quando se analisa a história da competição entre os Processos Leblanc e Solvay.

\section{Processo Leblanc}

O processo de Leblanc (ver Quadro 1) [10-14] ${ }^{1}$ foi implementado pelo médico francês Nicolas Leblanc (1742-1806) na esteira de um concurso aberto em 1783 pela Academia Francesa, por or- dem de Luís XVI, para um prémio de 2400 libras a ser atribuído a quem desenvolvesse um processo de fabrico da soda (carbonato de sódio) a partir do sal (cloreto de sódio). Até então, o composto era obtido por queima de matérias-primas vegetais, portanto renováveis: era extraído das cinzas de certas madeiras e plantas marinhas barrilha (por exemplo, o arbusto Salsola soda, cujas cinzas chegavam a atingir 30\% em carbonato de sódio), na Espanha Mediterrânica e nas Ilhas Canárias, e "kelp" (espécie Focus), na Escócia [12]. ${ }^{2}$ Com o aumento de procura do composto, que era utilizado no fabrico do sabão, vidro, papel, na nascente indústria têxtil, etc., em consequência do avanço da Revolução Industrial, as quantidades obtidas pela via natural começaram a mostrar-se insuficientes, além de que o acesso ao seu fornecimento, em França e Inglaterra, era problemático devido a guerras. Após estudar o assunto no laboratório, Leblanc divisou o processo descrito pelas equações no Quadro 1 e, em 1791, com o apoio do Duque de Orléans, ${ }^{3}$ montou uma fábrica em St. Denis, nos arredores de Paris, com capacidade para fabricar uma quantidade de soda da ordem de $300 \mathrm{~kg} / \mathrm{dia}$ (ou 100 ton/ano, o que no dealbar da Indústria Química era uma escala elevada!). O lançamento do empreendimento sofreu as vicissitudes da Revo- 
lução Francesa - o Duque de Orléans foi guilhotinado em 1793 e Leblanc foi obrigado a tornar públicos os detalhes da sua invenção a favor de quem os quisesse usar, tendo abandonado a fábrica, que só conseguiu recuperar em 1801. O abandono foi fatal para as instalações, que ficaram tão delapidadas que Leblanc, após a sua devolução, em situação económica difícil, não as conseguiu recuperar, também porque entretanto tinham surgido competidores com fábricas tecnologicamente mais evoluídas - e Leblanc suicidou-se em 1806 (e, claro, como Luís XVI tinha sido guilhotinado na Revolução, nunca chegou a receber o prémio!). metálicos, tecidos, etc., para já não falar da vegetação. Uma das primeiras leis ambientais inglesas (o "Alkali Act”, 1863) impôs um corte de 95\% nas respectivas emissões. Por isso, os gases começaram a ser absorvidos em água em torres de absorção cheias com carvão ou coque (um primeiro exemplo da instalação de equipamento antipoluição em fim-de-linha, vulgarizada nas últimas décadas do século $X X$, após a emergência do ambientalismo!) - mas como o efluente líquido era lançado nos rios, matava a respectiva fauna e flora (um primeiro exemplo de transferência de poluição industrial entre compartimentos ambientais!).

Quadro 1 Processo Leblanc

(1) Sal + Ácido sulfúrico $\rightarrow$ "Bolo de sal" (Sulfato de sódio) + Ácido clorídrico

$$
2 \mathrm{NaCl}+\mathrm{H}_{2} \mathrm{SO}_{4} \rightarrow \mathrm{Na}_{2} \mathrm{SO}_{4}+2 \mathrm{HCl}
$$

(2) "Bolo de sal" (Sulfato de sódio) + Carvão + Calcite $\rightarrow$ "Cinza negra"

$$
\mathrm{Na}_{2} \mathrm{SO}_{4}+4 \mathrm{C}+\mathrm{CaCO}_{3} \rightarrow \mathrm{Na}_{2} \mathrm{CO}_{3}+\mathrm{CaS}+4 \mathrm{CO}
$$

(3) Extracção da "cinza negra" com água $\rightarrow$ Carbonato de sódio + Resíduo alcalino

O Processo Leblanc, conjuntamente com o processo das câmaras de chumbo para o fabrico do ácido sulfúrico, constituíram a fundação da Química Industrial - foram os dois primeiros processos quimico-industriais montados em grande escala. ${ }^{4}$ Nas primeiras décadas do século XIX foram construídas diversas fábricas de soda em França, que preparavam já 10.000-15.000 toneladas do composto por ano [12]. Os ingleses também adoptaram o processo - a primeira fábrica inglesa foi construída em 1823, em Liverpool, por James Muspratt (1793-1886), um grande industrialista a quem a Indústria Química deve um primeiro grande avanço para a sua consolidação. Em meados do século XIX, a Inglaterra produzia já 70.000 toneladas por ano de soda [12] - e dominava a incipiente Indústria Química mundial.

Com o aumento de escala de produção do composto, tornou-se óbvio que o Processo Leblanc causava grandes danos no ambiente em redor das instalações. Por um lado, os fumos de ácido clorídrico que se libertavam na primeira etapa (Quadro 1) eram muito destrutivos para os materiais nos arredores da fábrica - edifícios, objectos
Por outro lado, a deposição no ambiente da "cinza negra" residual, produzida após extracção da soda na terceira etapa (Quadro 1), constituía também um problema: este material, formado por sulfureto de cálcio e excesso de carvão não reagido, co-produzido em grande quantidade (duas toneladas de resíduos por tonelada de soda) e sem utilidade, era deixado em volta das fábricas em grandes montões. Quando chovia, a chuva ácida proveniente da "lavagem" do ácido clorídrico no ar, por absorção deste gás nas gotas de água, reagia com o sulfureto de cálcio e libertava sulfureto de hidrogénio, provocando um cheiro terrível (este problema era mais grave quando a chuva era pouco intensa e não diluía muito o ácido que absorvia - com ácido mais concentrado, o ataque era mais eficaz). Além disso, com o tempo, acabava por ocorrer também oxidação do sulfureto a dióxido de enxofre, que se libertava para o ar e contribuía para a poluição atmosférica e respectivos danos. Por isso, acabou por se ter de remover os resíduos para o mar ou para minas abandonadas, mas o transporte acarretava custos adicionais (um primeiro exemplo dos custos da poluição que as empresas industriais que fabricam produtos químicos têm de suportar se não praticam QV!). Independentemente do destino dos resíduos sólidos, a incorporação neles do enxofre usado na preparação do ácido sulfúrico significava a sua perda (também um primeiro exemplo de custos acrescidos quando não se pratica uma boa economia atómica - Segundo Princípio da QV!). ${ }^{5}$

As perdas de materiais em resíduos pressionaram, mais tarde, o desenvolvimento de processos para os aproveitar (ver adiante). Por outro lado, o processo de fabrico era tecnologicamente complicado, o que limitava o aumento de escala. O pico de produção de soda pelo Processo Leblanc, no Reino Unido, foi da ordem de 280.000 toneladas por ano, à volta de 1880, decrescendo depois, quando surgiu o Processo Solvay, mas houve fábricas em funcionamento até aos anos vinte do século $X X$. O processo nunca foi usado nos EUA, onde a industrialização foi mais tardia e se usou o Processo Solvay desde o início [12]. No entanto, o Processo Leblanc foi um grande pilar da Indústria Química europeia durante o século XIX, muito contribuindo para a consolidação definitiva da sua emergência.

\section{Processo Solvay}

As limitações do Processo Leblanc levaram à investigação de processos alternativos, o que conduziu à invenção do Processo Solvay. Este processo (ver Quadro 2) [11,15-18] foi inventado pelo belga Ernest Solvay (18381922) e seu irmão Alfred, no início dos anos sessenta do século XIX - a primeira fábrica foi instalada em 1863 , em Couillet, Bélgica. O processo depressa se começou a espalhar por toda a Europa, nomeadamente para Inglaterra, em 1872, introduzido por Ludwig Mond (1839-1909), um imigrante alemão, que foi um inventor de destaque e um notório empreendedor no domínio da Indústria Química. A vantagem do Processo Solvay na competição com o Processo Leblanc resultou de ser tecnologicamente menos complicado e mais económico e, também, de ser mais verde: o amoníaco era recuperado, não havendo emissão de poluentes em quantidade significativa, e não produzia resídu- 
os tão inconvenientes (um primeiro exemplo da vantagem da verdura na prática da Química Industrial). posteriormente a respectiva produção estabilizou - e, não obstante as vantagens do Processo Solvay, o Processo

\section{Quadro 2 Processo Solvay}

(1) Borbulhamento de dióxido de carbono numa solução de sal saturada com amoníaco: separação de hidrogenocarbonato de sódio

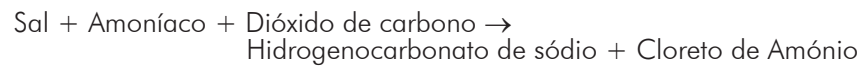

(2) Aquecimento do hidrogenocarbonato de sódio

$$
2 \mathrm{NaHCO}_{3} \rightarrow \mathrm{Na}_{2} \mathrm{CO}_{3}+\mathrm{CO}_{2}+\mathrm{H}_{2} \mathrm{O}
$$

(3) Recuperação do amoníaco

$$
2 \mathrm{NH}_{4} \mathrm{Cl}+\mathrm{CaO} \rightarrow 2 \mathrm{NH}_{3}+\mathrm{CaCl}_{2}+\mathrm{H}_{2} \mathrm{O}
$$

cluído que não. O Processo Leblanc foi sustentado em competição com um competidor mais eficiente porque foram encontradas aplicações para os respectivos resíduos (ver Quadro 3): por um lado, o ácido clorídrico passou a ser usado na produção de cloro e, a partir deste, de "pó de branqueação" $(\mathrm{CaClOCl}) ;{ }^{8}$ por outro, o enxofre do sulfureto de cálcio podia ser recuperado pelo processo de Claus (1888), após libertação de sulfureto de hidrogénio obtida por borbulhamento de dióxido de carbono, para ser reutilizado no fabrico do ácido sulfúrico usado na primeira reacção do processo.
Deve referir-se, no entanto, que presentemente, em termos dos padrões ambientais actuais, a deposição do cloreto de cálcio residual levanta problemas [16, 19, 20], o que tem levado a que continue ainda hoje a ser feita investigação para alterar e melhorar o Processo Solvay [19, 20]. Por outro lado, a descoberta de volumosos depósitos minerais de trona (sesquicarbonato de sódio, $\mathrm{Na}_{2} \mathrm{CO}_{3} \cdot \mathrm{NaHCO}_{3}$. $\mathrm{H}_{2} \mathrm{O}$ ) e de salmouras de carbonato de sódio, em certas regiões dos EUA, levou à descontinuação do processo naquele continente [16, 17, 21], por razões técnico-económicas: é tecnicamente mais fácil extrair os minerais e recristalizar o carbonato de sódio (ou cristalizá-lo a partir de salmoura) do que sintetizá-lo e o produto fica mais barato (redução do custo da ordem de metade). O Processo Solvay continua, porém, a ser usado no resto do mundo, já que o preço baixo da soda não permite acomodar o custo de transporte a longa distância.

\section{Substituição do Processo Leblanc pelo Processo Solvay}

Após a sua introdução, o Processo Solvay, mais eficaz e barato, foi substituindo o Processo Leblanc, mas não o eliminou imediatamente do mercado. Na Fig. 1 apresentam-se dados sobre a competição entre os dois processos no Reino Unido, desde a introdução do Processo Solvay até ao início do século $X X$ (produção anual por cada processo) [4,5]. A figura mostra que na década de oitenta do século XIX o novo Processo Solvay ganhou rapidamente quota de mercado ao processo vigente, cuja produção diminui (ocorreu "destruição criativa" [4]), mas

Quadro 3 Aproveitamento dos resíduos do Processo Leblanc

(1) Aproveitamento do $\mathrm{HCl}$ - Fabrico de "pó de branqueação" ( $\mathrm{CaClOCl}$ )

$$
\begin{aligned}
& 4 \mathrm{HCl}+\mathrm{MnO}_{2} \rightarrow \mathrm{Cl}_{2}+\mathrm{MnCl}_{2}+2 \mathrm{H}_{2} \mathrm{O} \\
& \mathrm{Cl}_{2}+\mathrm{Ca}(\mathrm{OH})_{2} \rightarrow \mathrm{CaClOCl}+\mathrm{H}_{2} \mathrm{O}
\end{aligned}
$$

Com recuperação do $\mathrm{Mn}$

$\mathrm{MnCl}_{2}+\mathrm{Ca}(\mathrm{OH})_{2} \rightarrow \mathrm{Mn}(\mathrm{OH})_{2}+\mathrm{CaCl}_{2}$

$\mathrm{Mn}(\mathrm{OH})_{2}+1 / 2 \mathrm{O}_{2} \rightarrow \mathrm{MnO}_{2}+\mathrm{H}_{2} \mathrm{O}$

(Processo de Weldon, 1869)

Alternativamente (fase gasosa, catalisador: $\mathrm{CuCl}_{2}$ )

$2 \mathrm{HCl}+1 / 2 \mathrm{O}_{2} \rightarrow \mathrm{Cl}_{2}+\mathrm{H}_{2} \mathrm{O}$

(Processo Deacon, 1868)

(2) Recuperação do Enxofre (processo de Clauss-Chance)

$$
\begin{array}{ll}
\mathrm{CaS}+\mathrm{CO}_{2}+\mathrm{H}_{2} \mathrm{O} \rightarrow \mathrm{CaCO}_{3}+\mathrm{H}_{2} \mathrm{~S} & \text { (Processo Chance, 1882) } \\
\mathrm{H}_{2} \mathrm{~S}+1 / 2 \mathrm{O}_{2} \rightarrow \mathrm{S}+\mathrm{H}_{2} \mathrm{O} & \text { (Processo Claus, 1988) }
\end{array}
$$

Leblanc manteve-se em funcionamento até aos fins da Primeira Guerra Mundial [12], tendo portanto os dois processos coexistido durante mais de quarenta anos.

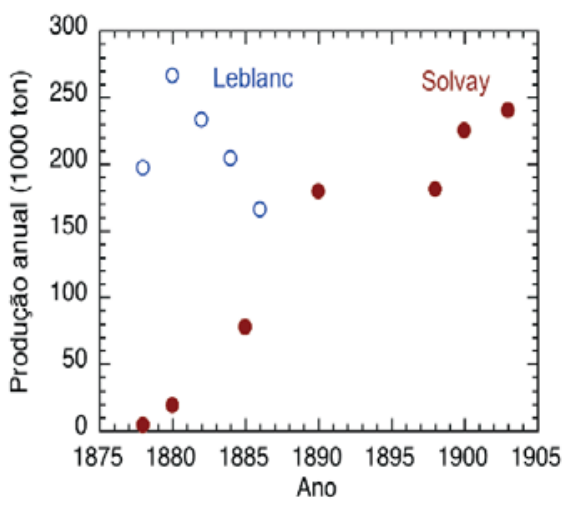

Figura 1 Substituição do Processo Leblanc pelo Processo Solvay após introdução deste no Reino Unido. Os dados para o traçado da figura foram obtidos em [4,5], presumindo-se, em face da sua origem, que os valores são expressos em ton imperiais (Reino Unido)

Embora as fontes históricas analisem a substituição [10,11], informação mais completa sobre esta foi proporcionada por um estudo recente do processo de substituição no âmbito da gestão da inovação da tecnologia [4,5]; este estudo analisou a substituição com vista a determinar se teria ocorrido o "efeito de barco à vela", ${ }^{7}$ tendo con-
Por outro lado, os utilizadores do Processo Leblanc passaram a realizar a segunda reacção de outro modo, na presença de hidróxido de cálcio ("cal apagada"), para preparar hidróxido de sódio ("soda cáustica"), cuja procura era crescente, em vez de soda - acoplando-lhe a reacção:

$\mathrm{Na}_{2} \mathrm{CO}_{3}+\mathrm{Ca}(\mathrm{OH})_{2} \rightarrow 2 \mathrm{NaOH}+\mathrm{CaCO}_{3}$

Como a soda cáustica obtida a partir do Processo Solvay era mais cara, as empresas que usavam o Processo Leblanc conseguiram uma vantagem competitiva quando transferiram a sua produção da soda para a soda cáustica.

Em suma, os praticantes do Processo Leblanc ao montarem um sistema eco-industrial centrado naquele processo (ver a Fig. 2), que Ihes permitia aproveitar resíduos e ampliar a gama de produtos fabricados, deram um passo importante para se manterem em competição com as empresas do Processo Solvay. A actividade industrial desenvolvida em torno do Processo Leblanc, à volta de 1880 , constitui um exemplo precoce da emergência da Ecologia Industrial - com mais de um século de avanço sobre a sua 
criação recente, que data dos anos noventa do século $\mathrm{XX}{ }^{9}$

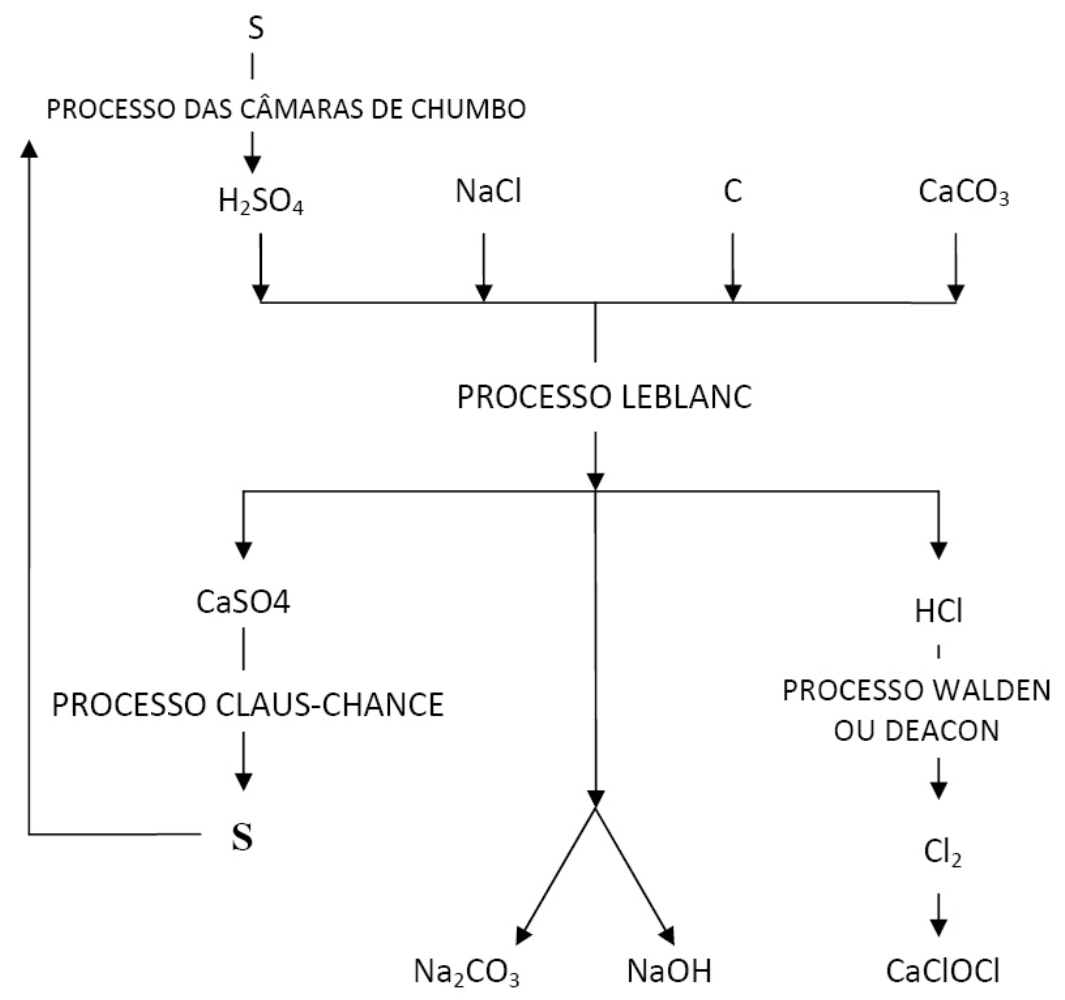

Figura 2 O sistema eco-industrial com cerne no Processo Leblanc como exemplo de Ecologia Industrial (Adaptado de [14])

No entanto, outros dois movimentos realizados pelas empresas do Processo Leblanc tiveram também importância para adiar a sua obsolescência. Primeiro, em 1891, as mais de quarenta empresas em actividade no Reino Unido aglomeraram-se numa única, a United Alkali Co (UAC), consolidando a sua actividade nas unidades mais eficientes.

Por outro lado, a UAC chegou a um acordo com o competidor (Mond), quanto a preços e quotas de mercado da soda, o que pode parecer irracional da parte deste último, já que dispunha de um processo tecnologicamente superior. A razão de ser do acordo tem por base factores não tecnológicos: a patente do Processo Solvay terminava em 1886, data em que este ficava acessível a todas as empresas, o que era uma vulnerabilidade dos seus utilizadores - a concorrente UAC poderia passar a usar o processo; outra vulnerabilidade resultava dos monopólios da produção do pó de branqueamento e da soda cáustica de que a UAC dispunha - que, em situação de "guerra comercial", Ihe permitiria baixar os preços da soda para retaliar sobre o adversário. Por isso, apesar de a sua tecnologia Solvay ser mais eficaz que rada de qualquer intenção, tal como no caso de Alfred Nobel [1]), mais de um século antes de se ter começado a falar em QV, nos fins do século XX, e a procurar definir princípios básicos $\mathrm{e}$ gerais para a sua implementação.

Além de ser curioso, o caso contém uma lição pertinente para a actualidade: a substituição inexorável do Processo Leblanc pelo Processo Solvay, após algumas décadas de competição, ${ }^{10}$ evidencia a força natural da QV como modo de implementar a Química Industrial. No entanto, os acontecimentos em torno da substituição mostram que esta não é apenas determinada pela "competitividade da verdura" dos processos - a substituição é um processo complexo, que envolve factores de outra natureza que não os da química e respectiva tecnologia. A substituição é um assunto com muito interesse actual, sendo preconizada pela $\mathrm{QV}$ - por exemplo, o REACH prevê a substituição de produtos perigosos, o que pode implicar substituição de processos, embora não avance com explicitações do modo como deve ser feita [9]. ${ }^{11}$

A montagem de um sistema eco-industrial com âmago no Processo Leblanc, fez diminuir o Factor E [22,23], que avalia a perda de átomos dos reagentes em resíduos de um processo, de cerca de 5,3 para cerca de 2 (ver Notas 5 e 9, valores aproximados em face da imprecisão dos dados históricos sobre as quantidades de materiais envolvidos no processo).

A inclusão do Processo Leblanc num sistema industrial que mimetizava os ecológicos aportou-lhe robustez sistémica, que foi determinante para o manter no mercado em competição com um processo tecnologicamente melhor - esteve na base do acordo sobre preços e quotas de mercado entre a UAC e o seu competidor, já que Ihe trouxe vantagens competitivas. Este caso mostra desde logo, precocemente, a importância da Ecologia Industrial quando se pretende montar a Indústria Química como um sistema industrial que metabolize resíduos em produtos vendáveis. 


\section{Notas}

${ }^{1}$ Sobre a bibliografia do Processo Leblanc: as Refs. [10] e [11] incluem análises históricas do desenvolvimento do processo, a segunda das quais detalhada e incluindo as vertentes humana e societária; o artigo [12] apresenta uma versão mais sumária (adequada para o ensino secundário); os artigos [13] e [14] contêm biografias de Leblanc, descrevendo as vicissitudes da implementação inicial do processo que tem o seu nome e da sua vida no âmbito da Revolução Francesa (o primeiro, mais breve, parece adequado para o ensino secundário).

${ }^{2}$ É interessante notar que presentemente o Sétimo Princípio da QV $[2,3]$ preconiza o uso de matérias-primas renováveis para o fabrico de produtos químicos. $\mathrm{O}$ caso presente mostra que esta prescrição tem limitações severas - desde o século XIX que o percurso histórico foi das matérias-primas renováveis para as minerais, porque as primeiras se mostraram insuficientes para satisfazer os requisitos intensos de produtos químicos da Civilização Industrial. Em consequência, provavelmente, o referido princípio só poderá ser cumprido em casos favoráveis e terá uma aplicação limitada.

${ }^{3}$ Leblanc era funcionário do Duque de Orléans, mas não muito ocupado - era médico, o que the deixava tempo livre para praticar química! De notar que, naquela altura, muitos dos praticantes da química eram médicos.

${ }^{4}$ Como mostra a primeira equação química do Processo Leblanc, o ácido sulfúrico é um dos reagentes do mesmo e, por isso, o desenvolvimento daquele processo pressionou o desenvolvimento do processo das câmaras de chumbo para o fabrico do ácido.

5 Genericamente, o aproveitamento das matérias-primas no processo de Leblanc era baixo: estimou-se que, em 1863, o consumo destas foi de 1.760 .000 toneladas, para produzir 280.000 toneladas de soda ([10], p. 283) - destes valores pode-se calcular um valor do Factor $\mathrm{E}$ (= $5,3)$, que, sendo elevado, evidencia que uma fracção elevada dos átomos aportados nos reagentes eram perdidos nos resíduos.

${ }^{6}$ Sobre a bibliografia do Processo Solvay: as Refs [11] e [15] incluem análises históricas do desenvolvimento do processo, a última em versão mais sumária (adequada para o ensino secundário); as Refs. [16] e [17] apresentam descri- ções detalhadas do processo tal como é praticado actualmente, informação sobre as aplicações actuais da soda, etc.; em [18] são incluídos detalhes técnicos do processo quando realizado segundo as melhores tenologias disponíveis.

7 O chamado "efeito do barco à vela" (introduzido por Gilfillan, 1935) consiste na aceleração da inovação numa tecnologia quando ameaçada pelo aparecimento de outra que aporta inovação radical; o nome provém de a construção de barcos à vela ter progredido muito quando surgiu o barco a vapor, segundo Gilfillan estudos recentes, porém, colocam esta conclusão em xeque [24].

${ }^{8}$ A fórmula é empírica e aproximada; a substância é uma mistura do hipoclorito $\mathrm{Ca}(\mathrm{ClO})_{2}$ e do hidroxicloreto $\mathrm{CaCl}_{2}$-$\mathrm{Ca}(\mathrm{OH})_{2}$, contendo também $\mathrm{Ca}(\mathrm{OH})_{2}$.

9 Após a montagem do sistema eco-industrial, o aproveitamento das matérias-primas melhorou: a partir de 9.000 unidades de matérias-primas obtinham-se 3.000 de produtos vendáveis ([10], $p$. 288), o que corresponde a um valor de Factor E = 2 (comparar com a Nota 5). Este valor é apenas ligeiramente superior ao valor teórico ideal do Factor $E=1,98$, calculado a partir das equações estequiométricas do Processo Leblanc admitindo que o cloro e o enxofre são totalmente recuperados e que não há outras perdas, pelo que parece demasiado optimista.

10 É interessante notar que no século $X X$, quando a Indústria Química já envolvia uma tecnologia muito mais evoluída, houve outro caso de substituição lenta com dois processos em competição para o fabrico do óxido de etileno [25]: Processo da cloro-hidrina:

$\mathrm{CH}_{2}=\mathrm{CH}_{2}+\mathrm{Cl}_{2}+\mathrm{H}_{2} \mathrm{O} \rightarrow \mathrm{ClCH}_{2} \mathrm{CH}_{2} \mathrm{OH}+\mathrm{HCl}$ $\mathrm{ClCH}_{2} \mathrm{CH}_{2} \mathrm{OH} \rightarrow\left(\mathrm{CH}_{2}\right)_{2}>\mathrm{O}+\mathrm{HCl}$ Processo da oxidação directa:

$\mathrm{CH}_{2}=\mathrm{CH}_{2}+\mathrm{O}_{2} \rightarrow\left(\mathrm{CH}_{2}\right)_{2}>\mathrm{O}$

$\mathrm{O}$ processo da cloro-hidrina surgiu nos anos trinta, o da oxidação directa nos anos quarenta. Este último, como mostram as equações, apresentava economia atómica superior (idealmente, $100 \%$ ) e não requeria reagentes problemáticos (cloro), pelo que era mais verde. Além disso, era tecnologicamente mais simples - e acabou por eliminar o processo da cloro-hidrina do mercado (este caso constituiu assim um outro exemplo de QV antes do tempo). No entanto, a eliminação só ocorreu nos anos oitenta, isto é, demorou também cerca de quatro décadas a ocorrer, apesar de, após um século de prática da Indústria Química, o respectivo progresso tecnológico ter acelerado. Tanto quanto o autor deste artigo tem conhecimento, esta substituição nunca foi analisada sob o ponto de vista da gestão da inovação tecnológica.

${ }^{11} \mathrm{Em}$ face da complexidade da Indústria Química, provavelmente o processo de substituição variará muito de caso para caso.

12 BREF é abreviatura de "Best available tecnique REFerence document".

\section{REFERÊNCIAS}

[1] A. A. S. C. Machado, "Alfred Nobel - O Primeiro Químico Verde?", Química Boletim da SPQ 103 (2006) 45-55.

[2] P. T. Anastas e J. C. Warner, Green Chemistry - Theory and Practice, Oxford UP, 1998, p. 30.

[3] A. A. S. C. Machado, "Química e Desenvolvimento Sustentável - QV, QUIVES, QUISUS", Química - Boletim da SPQ 95 (2004) 59-67.

[4] J. Hoewells, "The Response of Old Technology Incumbents to Technological Competition - Does the Sailing Ship Effect Exist?", J. Manag. Studies 39 (2002) 887-906.

[5] J. Hoewells, The Management of Innovation and Technology - The Shaping of Technology and Institutions of the Market Economy, SAGE Publications, 2005, p. 88-96.

[6] D. T. Allen, "Industrial Ecology", em D. T. Allen e D. R. Shonnard, Green Engineering -Environmentally Conscious Design of Chemical Processes, Prentice-Hall, 2002, p. 461-473.

[7] R. U. Ayres e L. W. Ayres, Handbook of Industrial Ecology, Elgar, 2002

[8] T. E. Graedel e B. R. Allenby, Industrial Ecology, $2^{\mathrm{a}}$ ed, Prentice-Hall, 2003

[9] Royal Society of Chemistry, A Brief Guide to Reach, RSC, 2008

[10] W. H. Brock, The Fontana History of Chemistry, Fontana, 1992, p. 276-293.

[11] W. A. Campbell, "The Alkali Industry", em C. A. Russell (ed.), Chemistry, Society and Environment - A New History of the British Chemical Industry, RSC, 2000, p. 75-106.

[12] D. F. Kiefer, "It Was All About Alkali", TCAW 11(1) (2002) 45-49.

[13] M. Sutton, "A Revolutionary Casuality", Chem. World 5(11) (2006) 54-57.

[14] R. P. Oesper, "Nicolas Leblanc (17421806)", J. Chem. Ed. 19 (1942) 567$-572 ; 20$ (1943) 11-20. 
[15] D. F. Kiefer, "Soda Ash, Solvay Style", TCAW 11(2) (2002) 87-90.

[16] R. D. A. Woode, "Sodium Carbonate", em R. Thompson (ed.), Industrial Inorganic Chemicals: Production and Use, 1995, p. 123-148.

[17] J. A. Kent, Kent and Riegels's Handbook of Industrial Chemistry and Bio-

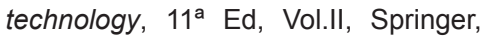
2007, p. 1185-1189.

[18] ESAPA - European Soda Ash Producers Association, Process BREF for Soda Ash, CEFIC (2004). ${ }^{12}$
[19] G. Steinhauser, "Cleaner Production in the Solvay Process: General Strategies and Recent Developments", J. Clean Prod. 16 (2008) 833-841.

[20] T. Kasikowski, R. Buczkowski e E. Lemanowska, "Clean Production in the Ammonia-Soda Industry: An Ecological and Economic Study", J. Env. Manag. 73 (2004) 339-356.

[21] D. S. Kostick, "Soda Ash", 2005 Minerals Yearbook, USGS (2006), p.70.1-70.10 .

[22] R. A. Sheldon, "Organic Synthesis -
- Past, Present and Future", Chem. Ind. (London) (1992) 903-906.

[23] A. A. S. C. Machado, "Métricas da Química Verde - A Produtividade Atómica", Química - Boletim da SPQ 107 (2007) 47-55.

[24] N. De Liso e G. Filatrella, "On Technology Competition: A Formal Analysis of the Sailing-Ship Effect", Econ. Innov. New Techn. 17 (2008) 593-610.

[25] G. H. Vogel, Process Development - From the Initial Idea to the Chemical Production Plant, Wiley-VCH, 2005, p. 6-7.

\section{Actualidade Científica}

A Estreia do Paládio (III) como Actor no Palco da Catálise

Uma equipa de Químicos da Universidade de Harvard demonstrou pela primeira vez a participação de complexos de paládio no estado de oxidação +3 em processos catalíticos de formação de ligações.

Esta descoberta vem fornecer um novo entusiasmo à química do paládio que poderá permitir o desenvolvimento de novas reacções.

O paládio é utilizado como catalisador numa grande variedade de reacções e a química dos seus estados de oxidação $0,+1,+2$ e +4 é bem conhecida. O estudante de graduação David C. Powers e o Professor Assistente de Química Tobias Ritter fizeram a nova descoberta enquanto investigavam o mecanismo de uma série de reacções de formação de ligações entre carbono e heteroátomos catalisadas por paládio.

Sempre se pensou que este tipo de reacções seguia por um ciclo catalítico envolvendo alternadamente $\mathrm{Pd}(\mathrm{II})$ e $\mathrm{Pd}(\mathrm{IV})$, onde cada centro activo metálico de $\mathrm{Pd}$ podia fornecer até dois electrões para formar a nova ligação.

Tendo por base experiências cinéticas, os investigadores propuseram um mecanismo alternativo envolvendo complexos contendo dois centros activos metálicos de $\mathrm{Pd}(\mathrm{III})$ como intermediários nas reacções, contribuindo cada Pd com um electrão para a formação de uma ligação C-heteroátomo (Nature Chemistry, DOI: 10.1038/nchem.246).

Não é garantido que o novo mecanismo possa ser aplicado de uma forma generalizada, mas a equipa pretende explorar o potencial do catalisador bimetálico $\mathrm{Pd}(\mathrm{III})$ numa variedade de reacções.

De acordo com Allan J. Canty da Universidade da Tasmânia, a equipa de investigadores da Universidade de Harvard "forneceu uma contribuição oportuna e fascinante para o actual rápido desenvolvimento da química orgânica envolvendo paládio nos seus estados de oxidação mais elevados e uma avaliação estimulante do potencial de envolvimento desses estados em síntese orgânica".
Canty demonstrou recentemente que os complexos análogos de $\mathrm{Pt}(\mathrm{III})$ também podem actuar como intermediários de reacção (Journal of the American Chemical Society 131 (2009) 7236).

(adaptado de Chemical \& Engineering News 87 (23) (2009) 10)

Helder Gomes 


\section{Where Chemistry Meets Physics}

The chemical societies of nine European

countries are

co-owners of

ChemPhysChem

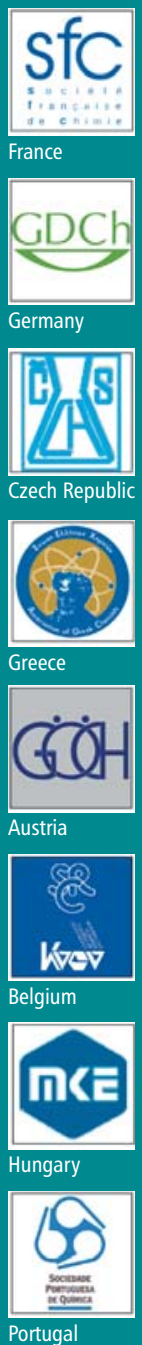

Subscribe now!

For further information

and to subscribe please

send an E-mail to:

cs-journals@wiley.com

(USA/Canada)

service@wiley-vch.de (Germany/Austria/Switzerland)

cs-journals@wiley.co.uk (all other areas)

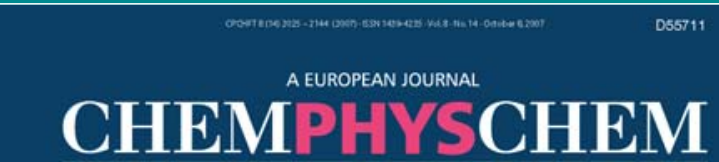

OF CHEMICAL PHYSICS AND PHYSICAL CHEMISTRY

Biphotonic fluorescence microscopy
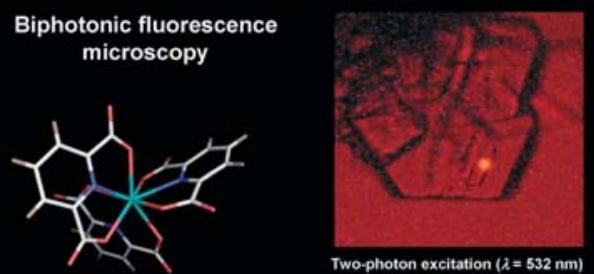$$
=
$$

Two-photon excitation $(\lambda=532 \mathrm{~nm})$
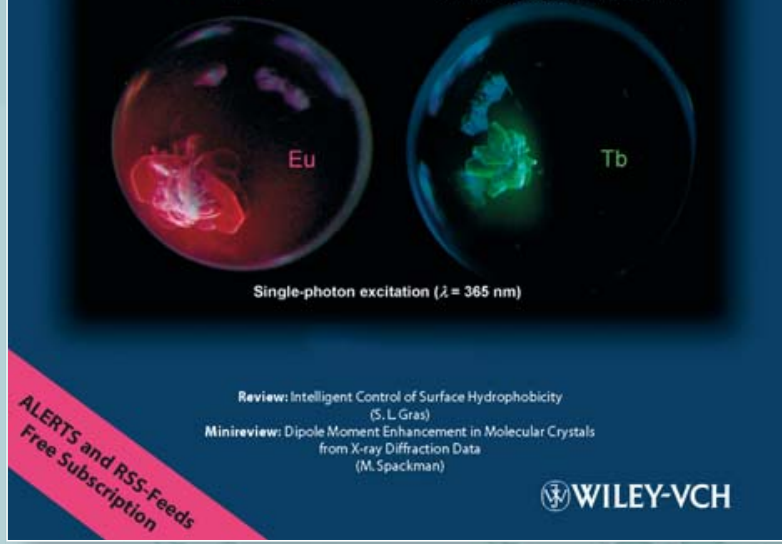

2008. Volume 9.

18 Issues.

ISSN 1439-4235 print ISSN 1439-7641 online

\section{ChemPhysChem is a leading journals for physical chemistry and chemical physics covering}

$\checkmark$ Solid-State and Soft-Matter Research

- Electro- and Photochemistry

- Femtochemistry and Nanotechnology

- Complex Systems

- Single-Molecule Research

- Clusters and Colloids

- Catalysis and Surface Science

- Biophysics and Physical Biochemistry

- Atmospheric and Environmental Chemistry

and many more topics
Chairmen of the

Editorial Advisory Board:

Frans C. De Schryver (Belgium)

James T. Hynes (France, USA)

Editor: Peter Gölitz

Deputy Editor: Melanie de Souza

\section{ChemPhysChem offers:}

- FREE Table of Contents

Early View - fully citable articles ahead of the printed version

- $\mathrm{RSS}$ feeds: Be automatically informed of new articles as soon as they are published online

\section{Visit ChemPhysChem online www.chemphyschem.org}

$\because$ (3)WILEY

InterScience

WILEY-VCH 


\section{Actualidade Científica}

\section{Grafeno em Circuitos Integrados}

As propriedades únicas do grafeno, uma camada monoatómica de grafite, tornam-no muito importante para várias aplicações electrónicas que começam a ser exploradas.

Num trabalho recentemente publicado por um grupo de investigação do Georgia Institute of Technology, EUA, no número de Junho da revista IEEE Electron Device Letters, foi analisada a resistividade eléctrica de várias nanotiras (nanoribbons) de grafeno, com larguras de $18 \mathrm{~nm}$ a $52 \mathrm{~nm}$.

Raghunath Murali e colaboradores verificaram que, em média, a sua resistividade é cerca de 3 vezes a de fios de cobre de idêntica secção, tendo observado, nos melhores casos, uma resistividade semelhante à do cobre.

Este estudo mostra que, a esta escala, estas nanotiras de garfeno podem substituir nanofios de cobre nas interligações de circuitos integrados.

Convém referir que a resistividade do cobre é, à escala macroscópica, independente das dimensões da amostra. Contudo, quando se atingem dimensões nanométricas, a resistividade aumenta, devido ao efeitos dos limites de grão e dos limites da amostra.

A possibilidade de, num espaço de cinco anos, se conseguirem fabricar circuitos integrados que usem motivos à escala dos $20 \mathrm{~nm}$, vem colocar estas nanotiras de grafeno no caminho dessa elevada densidade de integração, em alternativa ao cobre.

\section{Actualidade Científica}

\section{URINA COMO FONTE RENOVÁVEL DE HIDROGÉNIO}

A urina, o resíduo mais abundante na Terra, pode ser usada com matéria-prima para a produção de hidrogénio.

A tecnologia desenvolvida por um grupo de investigação da Universidade de Ohio, EUA, e descrita na revista Chemical Communications (DOI: 10.1039/ b905974a) promete não só uma alternativa mais barata do que aquela que se baseia na obtenção de hidrogénio a partir da água, mas também ajudar a purificar os resíduos aquosos municipais.

O grupo dirigido por Gerardine Botte desenvolveu um processo electrolítico que usa a ureia $\left(\mathrm{CO}\left(\mathrm{NH}_{2}\right)_{2}\right)$, o constituinte maioritário da urina, para a produção de hidrogénio.

Os átomos de hidrogénio encontram-se mais fracamente ligados na ureia do que na água, sendo por isso mais fácil de separar.
O potencial necessário para efectuar a electrólise da ureia é de $0,37 \mathrm{~V}$, valor inferior ao necessário para separar a molécula de água $(1,23 \mathrm{~V})$.

Este grupo de investigação desenvolveu um eléctrodo à base de níquel que, sendo barato, permite a oxidação selectiva e eficiente da ureia, com produção de azoto, hidrogénio e dióxido de carbono.

Apesar de no processo electroquímico se formar dióxido de carbono, este não se detecta nos gases libertados, dado que reage com o hidróxido de potássio da solução, formando carbonato de potássio $\left(\mathrm{K}_{2} \mathrm{CO}_{3}\right)$.

O processo foi inclusivamente optimizado para a utilização da urina em vez da ureia sintética.

No entanto a aplicação em larga escala desta tecnologia pode ser limitada pela rápida conversão da ureia em amónia por bactérias.
Por outro lado, a presença de elevados teores de sal em águas residuais contendo a ureia pode também levantar dificuldades de aplicação. 